\title{
SIMULATION OF LOW-GRADE COAL COMBUSTION IN REAL CHAMBERS OF ENERGY OBJECTS
}

\author{
Aliya Askarova ${ }^{a}$, Saltanat Bolegenova $^{b}$, Symbat Bolegenova $^{a}$, \\ Meruyert Beketayeva $^{a}$, Valeriy Maximov ${ }^{b}$, Aizhan Nugymanova ${ }^{a}{ }^{*}$, \\ PAVEL ŠAFAŘÍK ${ }^{c}$ \\ a al-Farabi Kazakh National University, Scientific Research Institute of Experimental and Theoretical Physics, \\ al-Farabi av. 71, 050040, Almaty, Kazakhstan \\ ${ }^{b}$ al-Farabi Kazakh National University, Physics and Technology Faculty, 050040, Almaty, Kazakhstan \\ ${ }^{c}$ Czech Technical University in Prague, Faculty of Mechanical Engineering, 16607 Praha 6, Prague, Czech \\ Republic \\ * corresponding author: nugymanova.aizhana@gmail.com
}

\begin{abstract}
The aim of the work is to create new computer technologies for 3D modelling of heat and mass transfer processes in high-temperature physicochemically reacting environments that will allow to determine the aerodynamics of the flow and heat and mass transfer characteristics of technological processes occurring in the combustion chambers in existing coal-fired thermal power plants of the Republic of Kazakhstan. The novelty of the research lies in the use of the latest information technologies of 3D modelling, which will enable project participants to obtain new data on complex heat and mass transfer processes when burning pulverized coal in real combustion chambers operating in Kazakhstan's Thermal Power Plants (TPP). A numerical simulation, including thermodynamic, kinetic and threedimensional computer simulation of heat and mass transfer processes when burning low-grade fuel, will allow finding optimal conditions for setting adequate physical, mathematical and chemical models of the technological process of combustion of burning high ash coals. The computer modelling methods proposed for the development are new and technically feasible, since coal-fired power plants all over the world use all types of coal. The developed technologies will allow replacing or eliminating the conduct of expensive and labour-consuming natural experiments on coal-fired power plants.
\end{abstract}

KEYwords: Combustion, modelling, thermal power plant, chemical reactions.

\section{INTRODUCTION}

Kazakhstan is currently a developed country with a population of around 18 million people spread unevenly over an area of 2.7 million $\mathrm{km}^{2}[1]$. Kazakhstan is rich in natural resources including coal, oil, natural gas and uranium and has a significant renewable potential from wind, solar, hydro-power and biomass [2]. Due to the rapid economic development of Kazakhstan and the related increase in demand for electricity, by 2020, a significant modernization of existing energy facilities is needed in addition to the construction of new power plants with a capacity of $20 \mathrm{GW}[3$.

At present, the Republic of Kazakhstan is dependent on fossil fuels for the power generation. Coal-fired plants lead to a greenhouse gas emissions and impacts on human health and the environment. According to the latest data quoted by the energy agency, in 2015, $\mathrm{CO}_{2}$ emissions reached $12.8 \mathrm{t} \mathrm{CO}_{2}$ per capita [2]. As shown in Fig. 1, 13\% of Kazakhstan's power is generated by hydroelectric power plants while the other $87 \%$ is from thermal-powered plants ( $75 \%$ coal-fired stations).

Thermal power plants in Kazakhstan, operating on coal, have a low efficiency, that is, most of the energy is not effectively used. Currently, the share

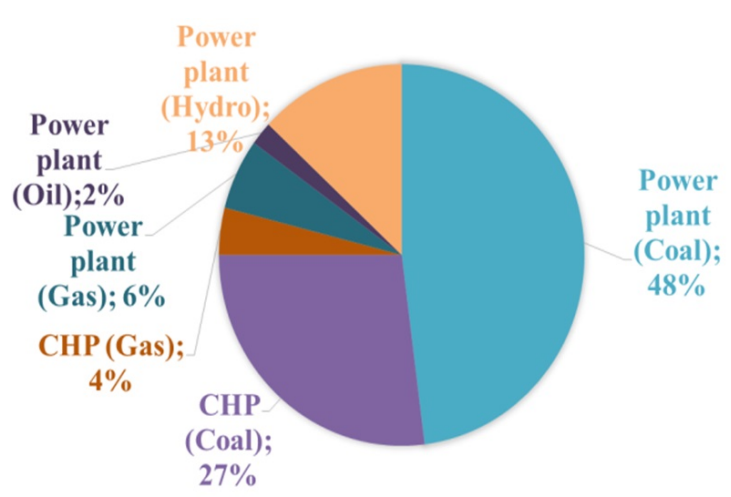

FigURE 1. Kazakhstan's electricity generating capacity $(\%)$.

of emissions from the sources of the energy complex of Kazakhstan with its high dependence on coal as the main energy source is $43.7 \%$ of the emissions of pollutants into the atmospheric air in Central Asia.

Emissions of thermal power plants account for up to $70 \%$ of the total volume of emissions of the energy complex (the Northern zone - 92\%, including Karaganda - 39-42\%, Pavlodar 38-39\%, Kazakhstan Republic). Emissions of industrial enterprises of Kazakhstan into the atmosphere are more than three million tons 


\begin{tabular}{lccc}
\hline Name & Symbol & Unit & Value \\
\hline Type of coal & $\mathrm{KR}-200$ & - & - \\
Milling disparity & $\mathrm{R}_{90}$ & $\%$ & 20 \\
Coal density & $\rho$ & $\mathrm{kg} / \mathrm{m}^{3}$ & 1350 \\
Gross calorific value & $Q_{s}$ & $\mathrm{MJ} / \mathrm{kg}$ & 18.55 \\
Ash & $A$ & $\%$ & 35.10 \\
Volatiles & $V$ & $\%$ & 22.00 \\
Humidity & $W$ & $\%$ & 10.60 \\
Carbon & $\mathrm{C}$ & $\%$ & 43.21 \\
Hydrogen & $\mathrm{H}$ & $\%$ & 3.6 \\
Oxygen & $\mathrm{O}$ & $\%$ & 5.24 \\
Sulfur & $\mathrm{S}$ & $\%$ & 1.04 \\
Nitrogen & $\mathrm{N}$ & $\%$ & 1.21 \\
\hline Chemical composition & $\mathrm{of} \mathrm{ash}(\mathrm{macro} \mathrm{components})$ \\
\hline & $\mathrm{SiO}_{2}$ & $\%$ & 60.20 \\
& $\mathrm{Al}_{2} \mathrm{O}_{3}$ & $\%$ & 25.5 \\
$\mathrm{Fe}_{2} \mathrm{O}_{3}$ & $\%$ & 5.85 \\
& $\mathrm{CaO} \mathrm{O}$ & 3.65 \\
$\mathrm{MgO}$ & $\%$ & 1.05 \\
& $\mathrm{TiO}_{2}$ & $\%$ & 0.95 \\
$\mathrm{SO}_{3}$ & $\%$ & 0.80 \\
$\mathrm{~K}_{2} \mathrm{O}$ & $\%$ & 1.65 \\
& $\mathrm{Na}_{2} \mathrm{O}$ & $\%$ & 1.06 \\
\hline
\end{tabular}

TABlE 1. Characteristics of Karaganda coal grade KR-200.

per year, of which $85 \%$ are 43 large enterprises. In emissions from various sources of the Unified Energy System, solid particles dominate - 35\%, sulphur dioxide $-31 \%$, carbon monoxide $-19 \%$ and nitrogen oxides $-14 \%$.

In order to reduce emissions and meet the growing demand for electricity, it is urgently necessary to develop and implement new cost-effective and environmentally friendly (safe) technologies, as well as to modernize existing energy supply facilities. Over the past decades, there has been an increased interest in forecasting the possibility of generating emissions from the industrial coal combustion. This is due to the lack of the ability to calculate emissions level based on solving individual equations, even using computers. Nevertheless, the prediction of formation of harmful substances in coal combustion systems is very common.

\section{Pulverized COAL CHARACTERISTICS}

Kazakhstan's coal reserves comprise 37 billion tons (4\% of world-estimated reserves) of mostly anthracitic and bituminous coals. Mines are in central Kazakhstan principally in the $2000 \mathrm{~km}^{2}$ Karaganda and $63 \mathrm{~km}^{2}$ Ekibastuz basin coalfields. At the current rates of production, Kazakhstan will have enough coal reserves for 200 years. However, speaking about the quality of Kazakh coal in comparison with the requirements of the world market, it is far from competitive. In the Karaganda basin, coal is produced with a sulphur content of 1.5 to $2.5 \%$ with high ash content (20-35\%). The use of this quality of coal leads to an incomplete combustion of fuel, which causes a high level of carbon and nitrogen compounds in the atmosphere. In addition, the degree of the ash content of coal has an adverse effect on the calorific value of coal [4]. The characteristics of the coal under the investigation are presented below in Table 1 .

The considered coals are difficult to enrich. Their inner component is almost indestructible (the organic part consists of plant matter, brought from mineral impurities deposited with plant residues, and the infiltration part of the mineral salts contained in the water circulating through the cracks). Thus, their enrichment does not justify the economic costs associated with the enrichment process.

\section{Modeling of COAL COMBUStion}

Thanks to advances in coal combustion modelling, there are many papers that are devoted to this topic. For example, in [5], the authors developed a coal combustion model based on CFD, which takes into account the role of the coal maceral content on the combustion process. In 6 6 authors describe the behaviour of the air-coal mixture using the Navier-Stokes equations for gas and particle phases, accompanied by a turbulence model. The undergoing chemical reactions are described by the Arrhenian kinetics. The system of PDEs is discretized using the finite volume method (FVM) and an advection upstream splitting method as the Riemann solver. The resulting ODEs are solved using the 4th-order Runge-Kutta method.

For a mathematical description of the two-phase flow of a monodisperse gas suspension, the authors of [7] use the Euler two-speed and two-temperature approach. In the present work, the authors used nonstationary equations of motion (Navier-Stokes), energy and mass transfer of the components for both phases, which are closed by the k- $\epsilon$ model of turbulence modified to take into account the effect of the dispersed phase. The authors solve the equations of the mathematical model using the SIMPLEC finite-difference algorithm with a constant time step modified to account for the variable density and the source term of the interfacial mass transfer in the continuity equation.

The authors of papers [8, 9] use the results of computer methods of Computational Fluid Dynamic to optimize the burning of brown coal.

The article [10] is devoted to numerical studies of plasma ignition and combustion of solid fuel in boiler furnaces and their industrial testing on existing boilers of thermal power plants. The authors of this work apply numerical simulation methods to the description and calculation of three-dimensional modelling of plasma activated fuel combustion in the furnace of in- 
dustrial boilers using the Cinar ICE software package developed at Imperial College, London.

In this paper, the CFD-software package FLOREAN (acronym: FLOw and REActioN) for 3-D modelling of coal-dust combustion in furnaces of real-sized boilers was used. The FLOREAN program package for computations was developed at the Institute of Heat Engineering and Combustion of the Technical University, Braunschweig (Germany). The 3D simulation in this program makes it possible to derive detailed information on the furnace performance, including fields of velocity, temperature, heat radiation, concentration distributions, etc., in the furnace axis and along the walls. The information derived during the simulation is useful for an estimation of combustion and for the design of an optimum furnace for operating in industries. The application of FLOREAN is also useful for an enhancement of combustion of various fuels in industrial boilers, optimization of operations and minimization of pollutant emissions.

The FLOREAN program used to describe both the gas phase and the particles uses the Euler approach, in which it is assumed that the velocity of the solid particles coincides with the gas velocity, i.e. the slip effect is negligible [11, 12. The authors of this article use this assumption in order to reduce computational costs. For example, in the flame region, solid components' concentration is determined using the balance equations for a monodisperse solid with an average particle diameter. To determine the density of the mixture, the authors proceeded from a homogeneous model, where the velocities of solid particles are considered to be equal to the local gas velocity. This model takes into account the heat exchange between solid particles and gas by a radiation.

The mathematical model used by the authors represents a complex system of nonlinear three-dimensional partial differential equations. They consist of the equations of continuity of the medium, the state of an ideal gas and the motion of a two-phase medium, heat transfer equations, chemical kinetics, and diffusion for the components of the reacting mixture, considering the radioactive and turbulent transport described by the $\mathrm{k}-\epsilon$ model of turbulence [13 15].

The authors use a simplified chemical combustion model, where there are no intermediate reactions and the formation of intermediate components, only the evolution of volatiles from coal, their oxidation to carbon oxides, and carbon burn ups are considered.

The complex physical and chemical processes occurring during the combustion of fuel are described by the conservation equations [16, 17]: the equations of conservation of mass, conservation of angular momentum and energy for the gas and solid phases. The gas flow is considered in the Eulerian system, while the dynamics of the solid phase is considered in the Lagrangian system.

Since there are no sources of mass, only the transformation of the constituent components takes place. In this case, the equation of the conservation of the mass equation (1) or the continuity equation takes the form (where the first term of the equation describes the flow non-stationary, the second term is the convective transport):

$$
\frac{\partial \rho}{\partial t}+\frac{\partial}{\partial x_{i}}\left(\rho u_{i}\right)=0
$$

$$
\begin{aligned}
& \frac{\partial\left(\rho u_{i}\right)}{\partial t}+\frac{\partial}{\partial x_{j}}\left(\rho u_{i} u_{j}\right)=-\frac{\partial p}{\partial x_{i}}+ \\
&+\frac{\partial}{\partial x_{j}}\left(\mu_{e f f}\left[\frac{\partial u_{i}}{\partial x_{j}}+\frac{\partial u_{j}}{\partial x_{i}}-\frac{2}{3} \delta_{i j} \frac{\partial u_{l}}{\partial x_{l}}\right]-\frac{2}{3} \delta_{i j} \rho k\right)+ \\
&+\rho g_{i}+F_{i}
\end{aligned}
$$

The first term of the equation (2) describes the non-stationary of the flow; the second - convective transport, the third and fourth terms - surface forces (pressure gradient and molecular diffusion), the fifth mass forces (gravity), and the sixth - external mass forces.

The energy conservation equation (3) considers the energy transfer due to conductivity, diffusion, and viscous dissipation:

$$
\begin{gathered}
\frac{\partial(\rho h)}{\partial t}+\frac{\partial}{\partial x_{i}}\left(\rho h u_{i}\right)=\frac{\partial p}{\partial t}+u_{i} \frac{\partial p}{\partial x_{i}}-\frac{\partial}{\partial x_{i}}\left(k_{e f f} \frac{\partial T}{\partial x_{i}}\right)- \\
-\frac{\partial}{\partial x_{i j}} h_{j^{\prime}} J_{j^{\prime}}+\left(\tau_{i j}\right)_{e f f} \frac{\partial u_{j}}{\partial x_{j}}+S_{h}
\end{gathered}
$$

where $h=\sum_{j} m_{j} h_{j}$ - enthalpy for ideal gases, $h=$ $\sum_{j} m_{j} h_{j}+\frac{p}{\rho}$ - enthalpy for incompressible flow of gas, $h=\int_{T_{\text {ref }}}^{T} c_{P, J} d T$ - enthalpy for flow $c_{P, J}$ diffusion substance, $k_{e f f}=k_{l}+k_{t}$ - effective thermal conductivity (the sum of laminar and turbulent thermal conductivity), $\left(\tau_{i j}\right)_{e f f}$ - effective stress tensor, $S_{h}$ - source term that takes heat into account due to chemical reactions and other volumetric energy sources (heat due to radiation, convective exchange between particles and the gas phase, and heat of combustion).

In the balance equation describing the components of the mixture, the variable value can be determined as follows:

mass fraction:

$$
\sum_{j} \frac{m_{j}}{m}=1 \quad\left[\frac{\mathrm{kg}}{\mathrm{kg}}\right] ; \quad c_{j}=\frac{m_{j}}{m} ;
$$

volume fraction:

$$
\sum_{j} \frac{V_{j}}{V}=1 \quad\left[\frac{\mathrm{m}^{3}}{\mathrm{~m}^{3}}\right] ; \quad c_{j}=\frac{V_{j}}{V} ;
$$

partial density:

$$
\sum_{j} \frac{m_{j}}{V}=\rho \quad\left[\frac{\mathrm{m}^{3}}{\mathrm{~kg}}\right] ; \quad c_{j}=\frac{m_{j}}{V} .
$$

Using the volume fraction is impractical, because it is necessary to introduce additional equations taking 
into account the dependence of volume on temperature. Therefore, in our model, authors use mass fraction. In general form, the equation for the concentration of the mixture components is written as:

$$
\frac{\partial\left(\rho c_{j}\right)}{\partial t}+\frac{\partial u_{i} c_{j}}{\partial x_{i}}=\frac{\partial}{\partial x_{i}}\left[\frac{\mu_{e f f}}{\sigma_{c_{n, e f f}}} \frac{\partial c_{j}}{\partial x_{i}}\right]+S_{c_{j}}
$$

In equation (7), the term takes into account the contribution of chemical reactions to changes in the concentration of components.

To study the turbulent burning flow of an industrial flame, the averaged conservation equations are used, supplemented by a two-parametric k- $\epsilon$ model of turbulence.

The release of the volatile coal is described by a first-order reaction. In this case, the pyrolysis process can be approximated by the first order of the reaction of the destruction of the coal particle, which proceeds uniformly throughout its volume. After the volatiles have been removed, carbon and inert ash remain in the coke residue. Heterogeneous reactions with the carbon of the coke residue are controlled by two competing processes: the diffusion of oxygen to the particle surface and the chemical kinetics of carbon oxidation on the particle surface. The modelling of the formation and reduction of nitrogen oxides is described by two stages that are not included in the general model of the fuel combustion. In the general model, it is assumed that the influence of chemical reactions of nitrogen-containing compounds can be neglected.

Simulation of the combustion process in the gas phase is a complex process involving numerous chemical reactions of fuel and oxidizer through the formation of intermediates and final products of the combustion. The task is further complicated because of the interaction between the turbulence and the kinetics of the combustion process, in view of the fact that turbulent reactive flows are characterized by sharp fluctuations in temperature and density, under the strong influence of exothermic reactions of the combustion process.

For many engineering applications, including zone fire modelling, the intermediate steps and reactions are of little interest, and only the "big picture" needs to be considered [18]. To describe the main features of a combustion system, Spalding introduced the concept of a Simple Chemically Reacting System (SCRS) [19. The SCRS involves a reaction between two reactants (fuel and oxidant) in fixed proportions by mass, to produce a unique product. An SCRS can be described as follows:

$$
1 \mathrm{~kg} \text { fuel }+r \mathrm{~kg} \mathrm{O}_{2}=(1+r) \operatorname{kg} \text { product }
$$

or

$$
1 \mathrm{~kg} \text { fuel }+s \mathrm{~kg} \text { air }=(1+s) \mathrm{kg} \text { product. }
$$

For example, in the case of stoichiometric combustion of pulverized coal in oxygen, Equation (7) indicates that $r$ is approximately equal to $(0.5 \times 32) / 12 \approx$ $1.33 \mathrm{~kg}=r_{\text {stoich }}$.
In this way, the model describes the global nature of the combustion process, where the complex mechanism of chemical kinetics is replaced by infinitely fast chemical reactions between the fuel and the oxidant.

For the simulation of the formation of combustion products in the coal dust flame, the kinetic model of chemical transformations was applied, which is true for a wide range of temperatures and reagent concentrations. However, a detailed simulation of all the reactions occurring (including all the intermediate reactions) is possible only in simple cases such as during carbon monoxide burning because of the great computational consumption or the absence of information on all intermediate reactions.

\section{Chemical kinetics of COAL COMBUSTION}

The burning coke residue is a slower process than volatile, and, therefore, determines the time of the complete combustion in the combustion chamber, which for coal dust in the combustion chamber is of the order of a few seconds. The overall reaction mechanism is complex, and the most important are the heterogeneous reactions occurring on the surface of coal particles $10-13$, as well as homogeneous 14.16 in the gas volume:

$$
\begin{gathered}
\mathrm{C}+\frac{1}{2} \mathrm{O}_{2} \longrightarrow \mathrm{CO} \\
\mathrm{C}+\mathrm{O}_{2} \longrightarrow \mathrm{CO}_{2} \\
\mathrm{CO}_{2}+\mathrm{C} \longrightarrow 2 \mathrm{CO} \\
\mathrm{H}_{2} \mathrm{O}+\mathrm{C} \longrightarrow \mathrm{CO}+\mathrm{H}_{2} \\
\mathrm{CO}+\frac{1}{2} \mathrm{O}_{2} \longrightarrow \mathrm{CO}_{2} \\
\mathrm{H}_{2}+\frac{1}{2} \mathrm{O}_{2} \longrightarrow \mathrm{H}_{2} \mathrm{O}
\end{gathered}
$$

In the first two 10 11 heterogeneous reactions, both oxides form at the boundary of two phases, that is, on the surface of the coke residue. At a temperature of about $926^{\circ} \mathrm{C}$, both $\mathrm{CO}$ and $\mathrm{CO}_{2}$ oxides are formed in equal amounts; with increasing temperature increases the rate of the reaction of carbon monoxide CO 20.

The formation of harmful substances modelled using reaction-kinetic models that take into account the occurrence of reactions in the presence of unstable products of intermediate reactions 21 .

Direct reaction between $\mathrm{CO}$ and $\mathrm{O}_{2}$ :

$$
\mathrm{CO}_{2}+\mathrm{O}_{2} \longrightarrow 2 \mathrm{CO}_{2}+\mathrm{O}
$$

The formed atom of oxygen atom $O$ does not lead to any rapid chain branched reactions. However, even with minimal presence of hydrogen $\left(\mathrm{H}_{2}\right), \mathrm{OH}$ radicals are formed. The process of carbon dioxide $\mathrm{CO}_{2}$ formation can be represented as a two-step reaction. The first stage is the decomposition of fuel molecules 
to carbon monoxide molecules $\mathrm{CO}$ and water $\mathrm{H}_{2} \mathrm{O}$, the second stage is the oxidation $\mathrm{CO}_{2}$. At high heats and a rather high content of oxygen, there is faster self-oxidation up to dioxide carbon $\mathrm{CO}_{2}$. This process can be described using a one-step reaction:

$$
\mathrm{C}_{x} \mathrm{H}_{y}+\left(x+\frac{y}{4}\right) \mathrm{O}_{2} \longrightarrow x \mathrm{CO}_{2}+\frac{y}{2} \mathrm{H}_{2} \mathrm{O}
$$

In a combustion chambers, the emission of carbon dioxide $\mathrm{CO}_{2}$ is one of the most difficult problems in modeling.

Sulphur $S$ in coal occurs in three forms: pyrite, organically bound to charcoal sulfur, or in the form of sulfates. Sulfur oxide $S O$ is formed at the beginning of the reaction zone from sulfur-containing molecules and is an important intermediate product.

During oxidative burning, sulphur dioxide $\mathrm{SO}_{2}$ (18) is formed from the sulfur of the fuel, which, dissolving in atmospheric moisture, forms sulphurous acid of moderate strength $\mathrm{H}_{2} \mathrm{SO}_{3}(19)$ :

$$
\begin{gathered}
\mathrm{S}+\mathrm{O}_{2} \longrightarrow \mathrm{SO}_{2} \\
\mathrm{SO}_{2}+\mathrm{H}_{2} \mathrm{O} \longrightarrow \mathrm{H}_{2} \mathrm{SO}_{3}
\end{gathered}
$$

Part of sulphur dioxide in air is oxidized to sulphur trioxide $\mathrm{SO}_{3}$ (20), which, in turn, when interacting with water vapour, produces strong sulfuric acid $\mathrm{H}_{2} \mathrm{SO}_{4}$, which, like sulfur dioxide, dissolves in atmospheric moisture (21).

$$
\begin{gathered}
2 \mathrm{SO}_{2}+\mathrm{O}_{2} \longrightarrow 2 \mathrm{SO}_{3} \\
\mathrm{SO}_{3}+\mathrm{H}_{2} \mathrm{O} \longrightarrow \mathrm{H}_{2} \mathrm{SO}_{4}
\end{gathered}
$$

The result of these processes are acid rains, from time to time falling on the surface of the Earth, not only in the vicinity of industrial enterprises, but also in neighbouring areas.

Also, some of the most harmful substances polluting the atmosphere are nitrogen oxides, such as nitrogen monoxide $\mathrm{NO}$-nitrogen dioxide $\mathrm{NO}_{2}$ nitrogen dioxide dimers - $\mathrm{N}_{2} \mathrm{O}_{3}, \mathrm{~N}_{2} \mathrm{O}_{4}, \mathrm{~N}_{2} \mathrm{O}_{5}$. Moreover, sources of oxides are both natural (soil emission of nitrogen oxides, lightning discharges, biomass burning) and anthropogenic (burning of fossil fuels, burning of combustible, etc.).

Thermal oxides - are formed due to oxidation of atmospheric nitrogen at high temperatures. The mechanism of their formation was proposed by Ya.B. Zeldovich, et al. 22, 23. It was proved that the formation of nitrogen oxides is not directly related to the combustion reaction, but goes through the dissociation of molecular oxygen at temperatures above $1527^{\circ} \mathrm{C}$. This mechanism consists of the following elementary reactions $(22,25)$ :

$$
\begin{aligned}
\mathrm{O}_{2} & \leftrightarrow 2 O \\
O+\mathrm{N}_{2} & \leftrightarrow N+N O \\
N+\mathrm{O}_{2} & \leftrightarrow O+N O
\end{aligned}
$$

$$
N+O H \leftrightarrow H+N O
$$

Thermal $N O_{x}$ es are formed at the maximal temperature, i.e. in that zone of a torch where the bulk of fuel has already burned down.

The mechanism of the formation of fast $N O_{x}$ was proposed by Fenimor according to the results of measuring the concentration of $\mathrm{NO}$ over a flat hydrocarbon flame 24-26]. The actual mechanism of the formation of nitrogen oxides in the flame front is more complex, since it involves the hydrocarbon radicals CH 24, 26, 28, :

$$
\begin{gathered}
C H+\mathrm{N}_{2} \leftrightarrow H C N+N \\
H C N+O H \leftrightarrow C N+\mathrm{H}_{2} \mathrm{O} \\
\mathrm{CN}+\mathrm{O}_{2} \leftrightarrow \mathrm{NO}+\mathrm{CO}
\end{gathered}
$$

Rapid nitrogen oxides are formed in front of the flame and depend mainly on the stoichiometric ratio at the place of their formation. Therefore, the required value $N O_{x}$ is formed only when the gas burns with the coefficient of excess air in the combustion zone being less than one. $N O$ can also be formed from nitrous oxide $\mathrm{N}_{2} \mathrm{O}$. This process is similar to the process of formation of thermal $N O_{x}$. However, in the presence of a third particle $M$ in this reaction, a molecule is also formed $\mathrm{N}_{2} \mathrm{O} 29 \mathrm{2}$ :

$$
\mathrm{N}_{2}+\mathrm{O}+\mathrm{M} \leftrightarrow \mathrm{N}_{2} \mathrm{O}+\mathrm{M}
$$

The $\mathrm{N}_{2} \mathrm{O}$ molecule can then react with the oxygen atom $O$ (30), the hydrogen atom $H$ (31), and the carbon monoxide molecule $C O(32)$ :

$$
\begin{gathered}
\mathrm{N}_{2} \mathrm{O}+\mathrm{O} \leftrightarrow 2 \mathrm{NO} \\
\mathrm{N}_{2} \mathrm{O}+\mathrm{H} \leftrightarrow \mathrm{NO}+\mathrm{NH} \\
\mathrm{N}_{2} \mathrm{O}+\mathrm{CO} \leftrightarrow \mathrm{NCO}+\mathrm{NO}
\end{gathered}
$$

When burning coal dust in the combustion chambers of boilers of thermal power plants, all three mechanisms of formation of nitrogen oxides take place.

There are many kinetic models of the formation of nitrogen oxides for a numerical simulation. The most common among them is the model proposed by Mitchell and Tarbell [27].

\section{BASIC CHARACTERISTICS OF THE BOILER}

The furnace chamber of the BKZ-75 boiler of the Shakhtinskaya TPP (Fig. 2), operated in the Karaganda region, was chosen as the object of the study. The boiler of this brand BKZ-75 has a block construction; it can be used when using brown and hard coal, peat, anthracite cobbles and lean coals. In Shakhtinskaya TPP, due to the presence of the nearby Karaganda coal deposit, mainly low-grade Karaganda coal (KR-200) with high ash content is burned.

The boiler BKZ-75 is a vertical water-tube structure; it has a U-shaped scheme for the movement 


\begin{tabular}{lccc}
\hline Name & Symbol & Unit & Value \\
\hline Height of the combustion chamber & $H$ & $\mathrm{~m}$ & 16.75 \\
Width of the combustion chamber & $b$ & $\mathrm{~m}$ & 6 \\
Depth of the combustion chamber & $\Gamma$ & $\mathrm{m}$ & 6.6 \\
Frontal and posterior wall area & $F_{f r}, F_{p}$ & $\mathrm{~m}^{2}$ & 90.675 \\
Area of the right side wall & $F_{s_{1}}$ & $\mathrm{~m}^{2}$ & 92.4 \\
Area of the left side wall & $F_{s_{2}}$ & $\mathrm{~m}^{2}$ & 110.55 \\
Top wall area & $F_{s}$ & $\mathrm{~m}^{2}$ & 27.72 \\
Bottom wall area & $F_{h}$ & $\mathrm{~m}^{2}$ & 7.26 \\
The cross-sectional area of the air channel burner & $F_{a}$ & $\mathrm{~m}^{2}$ & 0.12 \\
The cross-sectional area of the secondary air duct in the burner & $F_{s a}$ & $\mathrm{~m}^{2}$ & 0.25 \\
\hline
\end{tabular}

TABLE 2. Basic geometric parameters of the combustion chamber of the BKZ-75 boiler.

\begin{tabular}{|c|c|c|c|}
\hline Name & Symbol & Unit & Value \\
\hline Number of burners on the boiler & $N_{b}$ & pc. & 4 \\
\hline The performance of a single burner for fuel & $B_{b}$ & $\mathrm{t} / \mathrm{h}$ & 3.2 \\
\hline The primary air flow to the boiler & $V_{p a}$ & $\mathrm{Nm}^{3} / \mathrm{h}$ & 31797 \\
\hline Secondary air consumption per boiler & $V_{s a}$ & $\mathrm{Nm}^{3} / \mathrm{h}$ & 46459 \\
\hline The temperature of hot air & $t_{h a}$ & ${ }^{\circ} \mathrm{C}$ & 290 \\
\hline The excess air factor in the furnace & $\alpha$ & - & 1.2 \\
\hline Value of the air in leakage: & $\Delta \alpha$ & & \\
\hline Firebox and scallop & & & 0.1 \\
\hline Superheated & & & 0.03 \\
\hline Economizer & & & 0.02 \\
\hline Air Heater & & & 0.03 \\
\hline Estimated fuel consumption per boiler & $B_{c}$ & $\mathrm{t} / \mathrm{h}$ & 12.49 \\
\hline Cold air temperature & $t_{c a}$ & ${ }^{\circ} \mathrm{C}$ & 30 \\
\hline Pressure at the inlet & $P$ & $\mathrm{kPa}$ & 101300 \\
\hline Hydrodynamic resistance of the burner air mixture channel & $\Delta P$ & mm wt. & 67.1 \\
\hline The temperature of the air mixture & $t_{a m}$ & ${ }^{\circ} \mathrm{C}$ & 140 \\
\hline The wall temperature & $t_{w}$ & ${ }^{\circ} \mathrm{C}$ & 430.15 \\
\hline
\end{tabular}

TABLE 3. Technical parameters of the combustion chamber of the boiler BKZ-75 Shakhtinskaya TPP.

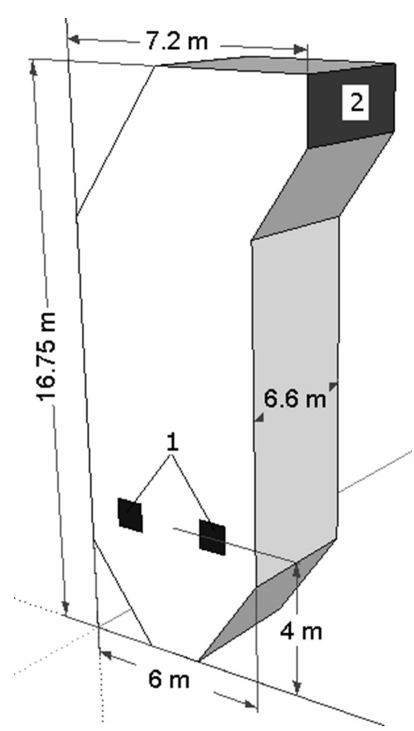

Figure 2. General view of the boiler BKZ-75 of Shakhtinskaya TPP. 1- burners; 2- region of the output section of the furnace chamber. of the working medium, based on natural circulation through the drum. The pipes in the front, rear screens and the lower part form in the furnace space the area of the cold funnel. Tables 2 and 3 show basic geometric parameters and also technical parameters of the combustion chamber of the BKZ-75 boiler.

For the numerical solution, the initial and boundary conditions were used, also the control volume method for solution of differential equations was applied [12, 28 30.

The furnace chamber of the BKZ-75 boiler is equipped with four axial-blade vortex pulverized-coal burners, which are in one stage of two burners on the side walls of the chamber and direct dust injection from individual dust preparation systems is used.

\section{RESUlTS OF NUMERICAL EXPERIMENTS}

The aerodynamics of two-phase turbulent flows during the combustion of pulverized coal causes the intensification of the entire combustion process. The aerody- 


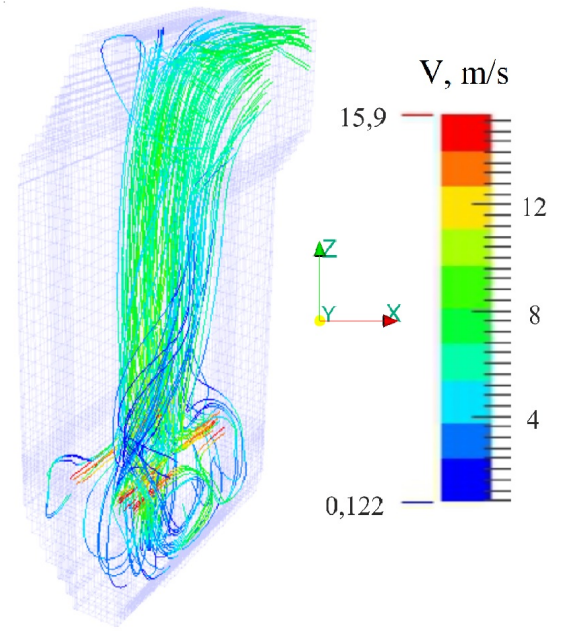

FiguRE 3. Streamlines and absolute velocity values in the volume of the combustion chamber of the boiler BKZ-75-39FB Shakhtinskaya CHPP.

namic basis of the entire combustion process in furnace devices is vortex transfer 31 36. The main role of the aerodynamic structure of the vortex flow is the perfect mixture of pulverized coal fuel and oxidant (air oxygen). From the analysis of the three-dimensional distribution shown in Fig. 3 it can be said that the flow of the air mixture with the combustion products has a vertical character in the region of the burners and in the lower part of the combustion chamber at a height from $2 \mathrm{~m}$ to $8 \mathrm{~m}$.

It can be seen that the full speed vector has maximum values ( $\mathrm{V}$ about $16 \mathrm{~m} / \mathrm{s}$ ) in the area of the burner. This is because the counter flow currents, blown from the burner devices and directed at maximum speed to the center of the furnace space, collide. And here, dissecting into several vortices, form a return flow up and down over the furnace space. This vortices character arises from turbulence due to the interaction of the air mixture with the oxidant. The presence of a volumetric vortex flow in the central region of the combustion chamber has a favourable effect on the combustion of the pulverized coal (heat transfer and mass transfer).

The temperature values reach their maximum values in the core region of the torch at an altitude of about three meters. Here, due to the vortex nature of the flow directed up and down the volume of the furnace (Figure 4), a maximum convective transfer and an increase in the residence time of coal particles are observed, because of which a temperature increase occurs in this zone. The fuel mixture and oxidizer (air) coming from the opposite burners, because of the vortex nature of the current, form a high-temperature core of the torch in the lower part of the combustion chamber (Fig. $4 \mathrm{a}$ left). On the height of the combustion chamber, a gradual decrease in temperature towards the exit from the furnace (Fig. 4a right) can be seen. At the exit $(X=7 \mathrm{~m})$ from the combustion chamber, the chemical processes are significantly

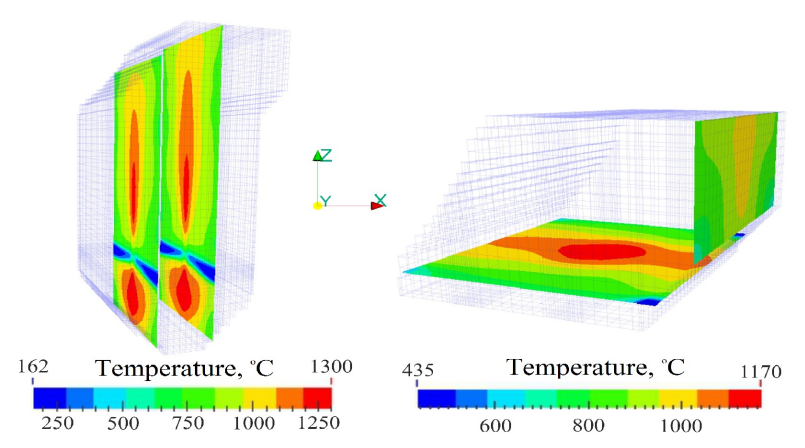

(A).

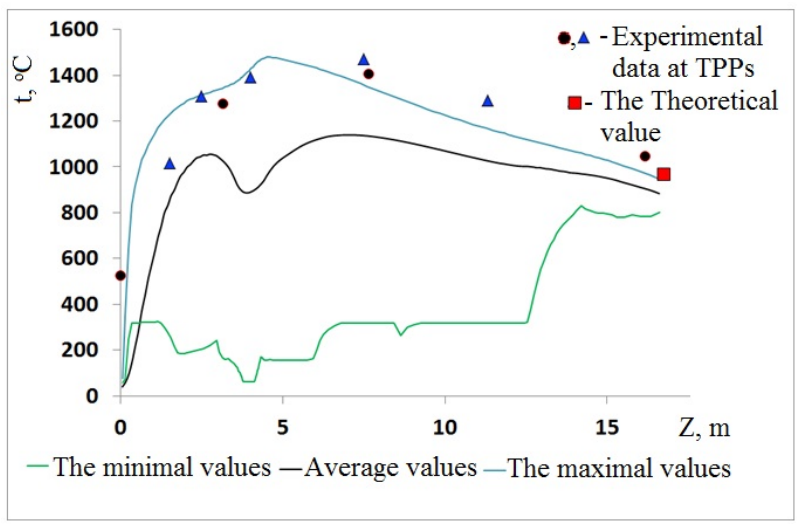

(B).

Figure 4. Distribution of the temperature: a) left $X=1.76 \mathrm{~m}$ and $X=4.22 \mathrm{~m}$; a) right $-Z=12.65 \mathrm{~m}$ and $X=7 \mathrm{~m}$ of the combustion chamber and b) verification of the results with the known data.

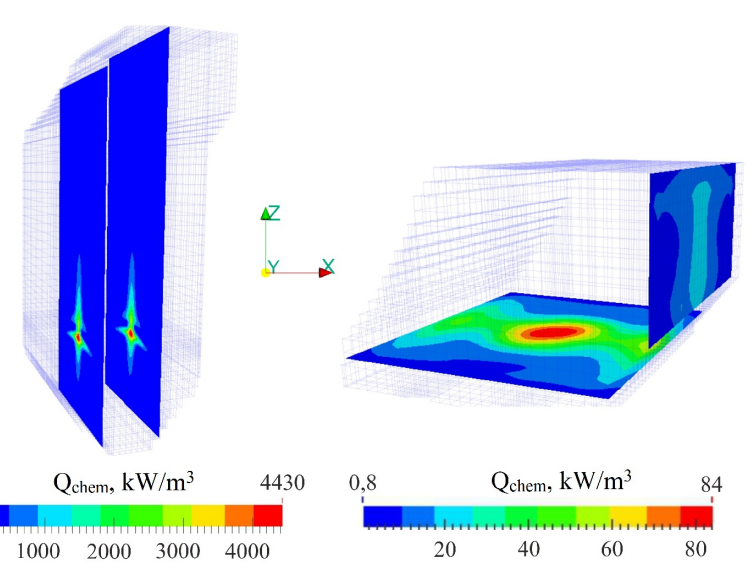

Figure 5. Distribution of the specific energy flux $Q_{\text {chem }}$ of chemical reactions in cross-sections: left $X=1.76 \mathrm{~m}$ and $X=4.22 \mathrm{~m}$; right $-Z=12.65 \mathrm{~m}$ and $X=7 \mathrm{~m}$ of the combustion chamber.

weakened, the temperature fields are equalized: in the rotary region of the furnace, the average temperature is $T=941^{\circ} \mathrm{C}$, and at the outlet from the combustion space $T=879^{\circ} \mathrm{C}$.

From Fig. 4b a good agreement with data from the theoretical calculation of the boiler and from data of TPP [37] can clearly be seen. 
Thermal power plants in Kazakhstan, operating on coal, have a low efficiency, which means that most of the energy is not effectively used. Currently, the share of emissions from the sources of the energy complex of Kazakhstan with its high dependence on coal as the main energy source is $43.7 \%$ of the emissions of pollutants into the atmospheric air in Central Asia. The analysis of the obtained results shows that in the area of the burner arrangement, there is an intensive mixing of the fuel with the oxidizer, accompanied by intensive chemical reactions, heat release and temperature increase, which is confirmed by the distribution of chemical energy along the height of the furnace (Fig. 5).

The analysis in Fig. 5 shows that the specific energy flow $Q_{\text {chem }}$ released by chemical reactions reaches its maximum value in the area of the furnace burner (about $5567 \mathrm{~kW} / \mathrm{m}^{3}$, Fig 5 left). As the pulverized coal flows to the exit, the intensity of the combustion process weakens and at the output from the combustion chamber $Q_{\text {chem }}$ is only $16 \mathrm{~kW} / \mathrm{m}^{3}$ (Fig. 5 right). This indicates the completion of oxidative processes here.

The distribution of $\mathrm{CO}_{2}$ concentration in the central part (Fig. 6a left) is less than at the outlet (Fig. 6a right). The final stages of the complete combustion of energy fuel, with the greatest amount of formation of combustion products of $\mathrm{CO}_{2}$, take place at the output area. Fig. 6b shows the verification of obtained results with known data [37] from real TPPs. It can be said that the maximal value of the $\mathrm{CO}_{2}$ concentrations are in a good compliance.

The concentration of sulfur oxides in sections: left - $X=1.76 \mathrm{~m}, X=4.22 \mathrm{~m}$; right - $Z=12.65 \mathrm{~m}$ and $X=7 \mathrm{~m}$ (Fig. 7) shows a similar distribution pattern as $\mathrm{CO}_{2}$. However, the quantitative values of sulfur dioxide $\mathrm{SO}_{2}$ are much lower than $\mathrm{CO}_{2}$. This is primarily related to the amount of sulfur content of the burned fuel, and secondly, it is related to the kinetics of the formation of sulfur oxides, that is, due to the low rate of chemical transformations. At the outlet, the average concentration of $\mathrm{SO}_{2}$ is $0.138 \%$.

The concentration of nitrous oxides, as shown in Fig. 8a left, has a minimal value at the burner zone and in the region where the injected flows meet. At the section $X=7 \mathrm{~m}$ (Fig. 8a right), or, in other word, at the outlet from the chamber, the average value of the $N O_{x}$ is equal to $940 \mathrm{mg} / \mathrm{Nm}^{3}$. From the comparison with experimental data and maximum permissible concentrations norms (MPC) 2, 3, 37, as it shown in Fig. $8 \mathrm{~b}$ it can be seen that obtained results correspond quite well to the real formation of $N O_{x}$ emissions with acceptable values for an ecologically clean operation of the energy fuel in this boiler 38 40.

A 3D computer simulation of the combustion of pulverized coal fuel allows for better understanding of the problems of computational fluid dynamics (CFD), mathematical and numerical modelling of solid fuel combustion processes, and the mechanism of a chem-

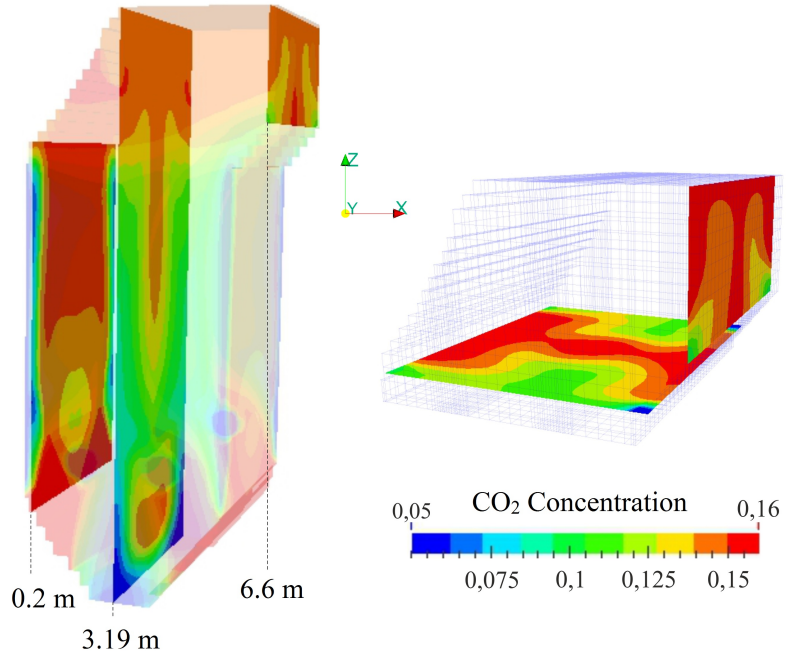

(A).

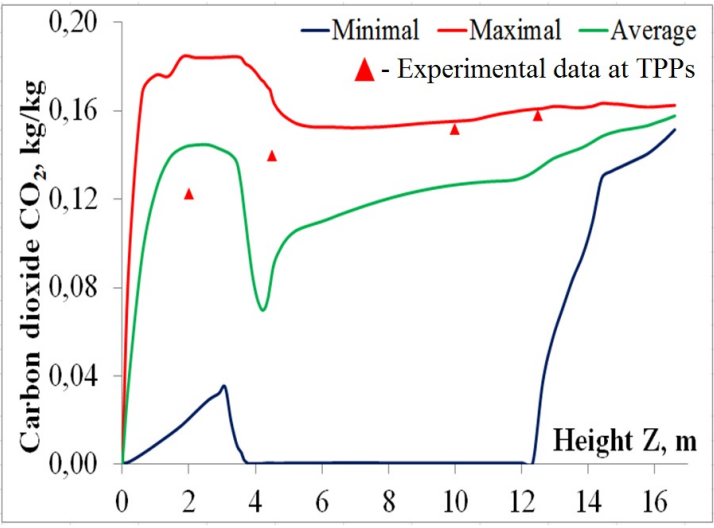

(B).

FiguRE 6. Distribution of the $\mathrm{CO}_{2}$ concentrations in cross-sections: a) left $-X=1.76 \mathrm{~m}$ and $X=4.22 \mathrm{~m}$; a) right $Z=12.65 \mathrm{~m}$ and $X=7 \mathrm{~m}$ of the combustion chamber and $b$ ) verification of the results with the known data.

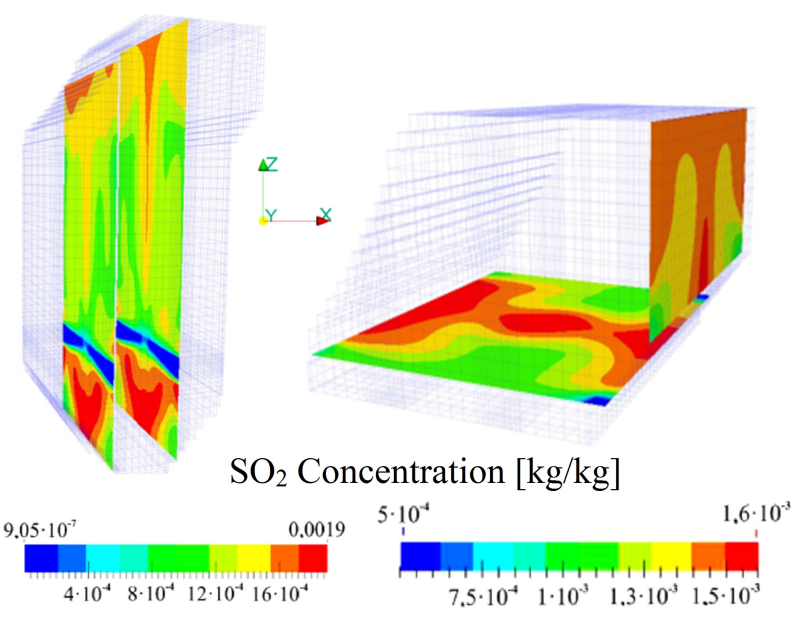

Figure 7. Distribution of the $\mathrm{SO}_{2}$ concentrations in cross-sections from three-dimensional calculation model: left $-X=1.76 \mathrm{~m}$ and $X=4.22 \mathrm{~m}$; right $-Z=$ $12.65 \mathrm{~m}$ and $X=7 \mathrm{~m}$ of the combustion chamber. 


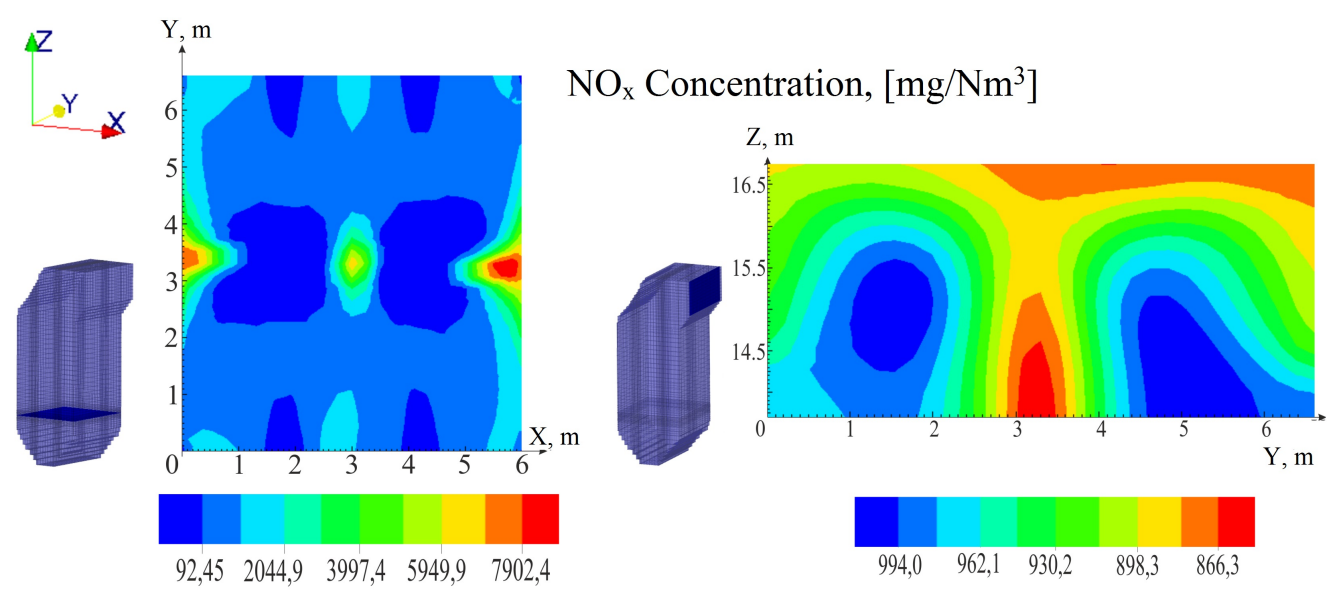

(A).

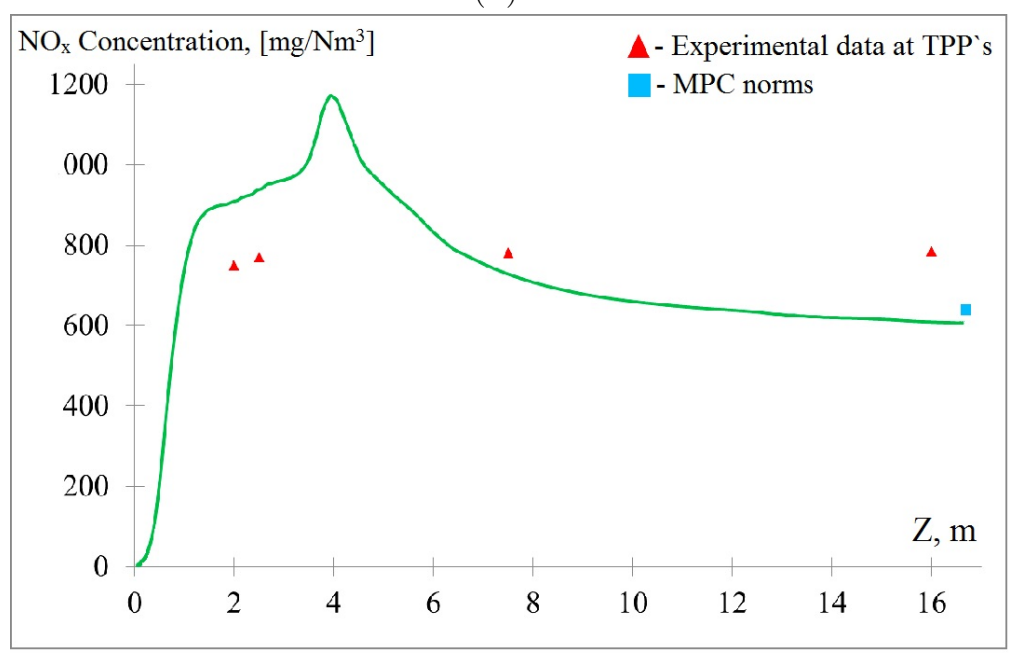

(B).

FiguRE 8. Distribution of the $N O_{x}$ concentrations in cross-sections: a) left - $X=1.76 \mathrm{~m}$ and $X=4.22 \mathrm{~m}$; a) right $Z=12.65 \mathrm{~m}$ and $X=7 \mathrm{~m}$ of the combustion chamber and b) verification of the results with the known data.

ical interaction between combustion products. The results of the conducted research contribute to the solution of the actual problems of thermal physics, technical physics, thermal power engineering and environmental safety, since they make it possible to give recommendations on optimization of burning processes of low-grade energy fuels in order to increase energy efficiency and improve the ecological situation and create a "clean" energy production.

\section{Conclusion}

Concluding the results of the conducted research, we can propose the new physical-mathematical and chemical models of simulations of a low-grade coal combustion in real chambers of energy objects. The used method give an adequate character of the processes of heat and mass transfer and formation about emissions of harmful substances during the burning of low-quality Karaganda coal of grade KR-200 with a high ash content (more than 35\%) in the combustion chamber of the existing power boiler BKZ-75 of Shakhtynskaya TPP. As shown in figures above, concentrations of carbon dioxide $\mathrm{CO}_{2}$ and nitrogen oxides $N O_{x}$ are in a good agreement with the experimental data, received from a real thermal power plant [37]. Also, nitrogen oxides $N O_{x}$ concentrations were compared with the limit value for Kazakhstan Republic TPP's. By a comparison of numerical experiment results held in this work with natural data from the TPP, we can claim that the observed method of research of combustion processes is reliable. The results carried out in this work and the used method of computational study can be useful in the design and development of new as well as in the improvement of existing combustion chambers of power boilers of TPP.

\section{ACKNOWLEDGEMENTS}

This work has been supported financially by the Ministry of Education and Science of the Republic of Kazakhstan: 1) Grant No. BR05236730 as part of the program of targeted financing of research works for 2018-2020; 2) Grant Financing Projects for 2018-2020 No. AP05132988 and No. AP05133590. 
The last author, P. Šafařík, expresses acknowledgements for support by the Project No. CZ.216/3.1.00/21569 Centre 3D Volumetric Anemometry.

\section{REFERENCES}

[1] BBC. Kazakhstan country profile. https:

//www.bbc.com/news/world-asia-pacific-15263826 2018. Accessed: 20 March 2018.

[2] International Energy Agency. https://www.iea.org/countries/Kazakhstan/.

[3] R. Pomfret. Kazakhstan's 2030 strategy: Goals, instruments and performance. In Proceedings of the American Economic Association annual conference in Philadelphia on 4 January 2014, p. 21. 2014.

[4] A. Askarova, M. Buchmann. Structure of the flame of fluidized-bed burners and combustion processes of high-ash coal. In Gesell Energietech, Combustion and Incineration. Proceedings of the18th Dutch-German Conference on Flames, vol. 1313, pp. 241-244. VDI Berichte, 1997.

[5] R. I. Backreedy, L. M. Fletcher, L. Ma, et al. Modelling pulverised coal combustion using a detailed coal combustion model. Combustion Science and Technology 178(04):763-787, 2006. DOI: $10.1080 / 00102200500248532$

[6] R. Straka, J. Makovička. Model of pulverized coal combustion in a furnace. Kybernetika 43(06):879-891, 2007 .

[7] J. Van Doormaal, G. Raithby. Enhancements of the simple method for predicting incompressible fluid flows. Numerical Heat Transfer 7(2):147-163, 1984. DOI:10.1080/01495728408961817

[8] R. Leithner. Numerical Simulation. Computational Fluid Dynamics CFD: Course of Lecture. IWBT, 2006.

[9] R. Leithner, H. Mueller. Cfd studies for boilers. In Second M.I.T. Conference on Computational Fluid and Solid Mechanics, pp. 172-180. Cambridge, 2003.

[10] E. Karpenko, et al. Mathematical modeling of the processes of solid fuel ignition and combustion at combustors of the power boilers. In Proceedings of the 7th International Fall Seminar on Propellants, Explosives and Pyrotechnics, vol. 7, pp. 672-683. Xian, 2007. DOI:10.1109/TPS.2014.2345871

[11] A. Askarova, V. Messerle, A. Ustimenko, et al. Numerical simulation of pulverized coal combustion in a power boiler furnace. High Temperature 53(05):445-452, 2015. DOI:10.1134/S0018151X15020030

[12] H. Müller. Numerische Berechnung Dreidimensionaler Turbulenter Strömungen in Dampferzeugern mit Wärmeübergang und Chemischen Reaktionen am Beispiel des SNCR-verfahrens und der Kohleverbrennung. Fortschritt-Berichte VDI-Verlag 268(6):158, 1992.

[13] A. Askarova, S. A. Bolegenova, V. Maximov, et al. Computational method for investigation of solid fuel combustion in combustion chambers of a heat power plant. High Temperature 53(05):751-757, 2015. DOI:10.1134/S0018151X15040021
[14] A. Askarova, et al. CFD study of harmful substances production in coal-fired power plant of Kazakhstan. Bulgarian Chemical Communications 48(E):260-265, 2016.

[15] R. Leithner, A. Askarova, S. Bolegenova, et al. Computational modeling of heat and mass transfer processes in combustion chamber at power plant of kazakhstan. MATEC Web of Conferences 76:06001, 2016. DOI:10.1051/matecconf/20167606001

[16] M. Gorokhovski, et al. Stochastic simulation of the spray formation assisted by a high pressure. In Proceedings of the 6-th International Symposium on Multiphase Flow, Heat Mass Transfer and Energy Conversion. Book Series: AIP Conference Proceedings, vol. 1207, pp. 66-73. 2010.

[17] A. Askarova, et al. Combustion of low-rank coals in furnaces of kazakhstan coal-firing power plants. VDI Berichte pp. 497-502, 2007.

[18] M. L. Janssens. An Introduction to Mathematical Fire Modeling. Technornic Publishing Company, Inc, 2000.

[19] D. Spalding. Combustion and Mass Transfer. Oxford: Pergamon Press, 1979.

[20] L. Pashkov. Fundamentals of the theory of combustion: a training manual. MEI (TU), 2002.

[21] GOST 30404-2000. Solid mineral fuel. Determination of sulfur forms. standard, Interstate Council for Standardization, Metrology and Certification: Standards Publishing House, Minsk, 2001.

[22] A. S. Askarova, V. E. Messerle, A. B. Ustimenko, et al. Reduction of noxious substance emissions at the pulverized fuel combustion in the combustor of the BKZ-160 boiler of the Almaty heat electropower station using the "Overfire Air" technology. Thermophysics and Aeromechanics 23(1):125-134, 2016. DOI:10.1134/S0869864316010133

[23] J. Zeldovich. The oxidation of nitrogen in combustions and explosions. Journal Acta Physicochemica 21:557-628, 1946.

[24] B. Epple. Modellbildung und simmulation von strömungs, reaktions- und NOx-bildungsvorgängen in technischen feuerungen, vol. 6. VDI-Verlag, 1993.

[25] A. Askarova, A. Bekmukhamet, S. Bolegenova, et al. 3-D Modeling of Heat and Mass Transfer during Combustion of Solid Fuel in Bkz-420-140-7C Combustion Chamber of Kazkhstan. Journal of Applied Fluid Mechanics 9(02):699-709, 2016. DOI:10.18869/acadpub.jafm.68.225.22881

[26] R. Leithner, et al. Firing technique measures for increased efficiency and minimization of toxic emissions in Kazakh coal firing. In Proceedings of the 19th German Conference on Flames, VDI Gesell Energietechn; Verein Deutsch Ing., Combustion and Incineration, vol. 1492, p. 93. VDI-Verlag, 1999.

[27] J. Mitchell, J. Tarbell. A kinetic model of nitric oxide formation during pulverized coal combustion. AIChE Journal 28:302-320, 1982. DOI:10.18869/acadpub.jafm.68.225.22881 
[28] A. Askarova, S. Bolegenova, A. Bekmukhamet, et al. Using 3D Modeling technology for investigation of conventional combustion mode of BKZ-420-140-7C combustion chamber. Journal of Engineering and Applied Sciences 9(01):24-28, 2014. DOI:10.3923/jeasci.2014.24.28

[29] A. S. Askarova, E. I. Karpenko, V. E. Messerle, A. Ustimenko. Plasma enhancement of combustion of solid fuels. High Energy Chemistry 40(2):111-118, 2006. DOI:10.1134/S0018143906020081.

[30] A. S. Askarova, V. E. Messerle, A. Ustimenko, et al. Numerical simulation of the coal combustion process initiated by a plasma source. Thermophysics and Aeromechanics 21(6):747-754, 2014. DOI:10.1134/S0869864314060092.

[31] V. E. Messerle, A. Ustimenko, A. S. Askarova, A. O. Nagibin. Pulverized coal torch combustion in a furnace with plasma-coal system. Thermophysics and Aeromechanics 17(3):435-444, 2010. DOI:10.1134/S0869864310030145.

[32] A. Askarova, S. Bolegenova, V. Maximov, et al. Numerical Research of Aerodynamic Characteristics of Combustion Chamber BKZ-75 Mining Thermal Power Station. Procedia Engineering 42:1250-1259, 2012. DOI:10.1016/j.proeng.2012.07.517

[33] S. Bolegenova, et al. Three-Dimensional modeling of heat and mass transfer during combustion of low-grade
Karaganda coal. In Proceedings of the 22nd National Congress of Chemical and Process Engineering, CHISA 2016 and 19th Conference on Process Integration, Modeling and Optimization for Energy Saving and Pollution Reduction, vol. 2, p. 1102. Prague, Czech republic, 2016.

[34] A. Gabitova, et al. Control of harmful emissions concentration into the atmosphere of megacities of Kazakhstan Republic. In International Conference on Future Information Engineering (FIE2014), IERI Procedia, pp. 252-258. Beijing, 2014.

[35] M. Beketayeva, et al. Numerical modeling of turbulence characteristics of burning process of the solid fuel in BKZ-420-140-7C combustion chamber. International Journal of Mechanics 8(1):112-122, 2014.

[36] A. Askarova, et al. Investigation of turbulence characteristics of burning process of the solid fuel in BKZ 420 combustion chamber. In WSEAS Transactions on Heat and Mass Transfer, vol. 9, pp. 39-50. 2014.

[37] B. Alijarov, M. Alijarova. Combustion of Kazakh coals in thermal power stations and large-power boiler houses. Almaty, 2011.

[38] E. Heierle, et al. CFD code FLOREAN for Industrial Boilers Simulations. In WSEAS Transactions on Heat and Mass Transfer, vol. 4, pp. 98-107. 2009.

[39] S. Bolegenova, et al. Numerical experimenting of combustion in the real boiler of CHP. International Journal of Mechanics 7(3):343-352, 2013.

[40] A. Askarova, S. Bolegenova, V. Maximov, A. Bekmuhamet. Mathematical simulation of pulverized coal in combustion chamber. Procedia Engineering 42:1150 - 1156, 2012. DOI:10.1016/j.proeng.2012.07.507 